\title{
The Shift-Work Accident Rate is More Related to the Shift Type than to Shift Rotation
}

Thomas Kantermann, ${ }^{1}$ Damien Haubruge, ${ }^{2}$ and Debra J. Skene ${ }^{1}$

${ }^{1}$ Centre for Chronobiology, Faculty of Health and Medical Sciences, University of Surrey, Guildford, Surrey, UK; ${ }^{2}$ ArcelorMittal, INDUSTEEL Belgium, Charleroi, Belgium

Address correspondence to Thomas Kantermann, $\mathrm{PhD}$, University of Groningen, Chronobiology

- Centre for Behaviour and Neurosciences, Nijenborgh 7, 9747 AG Groningen, The Netherlands; E-mail: thomas@kantermann.de

Running Head: Shift-Work Accident Rate

Received 17 March 2012; revised manuscript accepted 23 May 2012 


\begin{abstract}
The current study investigated the accident rates across morning, late, and night shifts in rotating shift-workers employed in two different shift rotations at the same steel work factory. A retrospective analysis has been performed of accident data $(\mathrm{N}=578)$ over a 5-year period $(2003$ through 2007) of 730 male shift-workers employed in either a clockwise (mean age of the workers 38.1 \pm SD 9.8 years) or counterclockwise rotation (mean age $38.0 \pm$ SD 10.1 years) with comparable work conditions. The overall accident rate across the 24-hour day was not significantly different between clockwise and counterclockwise shift rotation. In both shift-work rotations, morning shifts as opposed to night shifts exhibited a significantly higher accident rate. There was no significant difference between late shifts and morning or night shifts in either shift rotation. The increased accident rate in the morning shift at this steel factory could be related to the early starting time of the shift and to this shift being more labor intensive in both shift rotations. These findings suggest that work-related factors must be considered in addition to shift-work schedules when investigating accident rates in rotating shift-workers.
\end{abstract}

Key Words: accident, clockwise rotation, counterclockwise rotation, sleep deprivation, work schedule. 


\section{INTRODUCTION}

Shift-work affects the health of a significant number of workers (Karlsson et al. 2003; Knutsson 2003; Kantermann et al. 2010) but to date the contribution of shift-work schedules to risk remains unclear. This concerns, for example, how the timing and rotation of schedules should be arranged to decrease and minimize adverse effects (Folkard 1992). Whereas especially night work has been reported to show an increased risk of being involved in an accident at work (Folkard and Tucker 2003; Folkard et al. 2005), previous studies have also shown influences of other factors as, inter alia, sleep deprivation due to an early start of the morning shift, length of time on shift, the number of consecutive shifts, or occupation (Costa 2003; Folkard et al. 2005). However, such influences on the accident rate have also been found in occupations with otherwise comparable work tasks across individual shifts (Folkard 1997). These findings are supported by human circadian studies on alertness, vigilance, sleepiness and fatigue, showing distinct peaks and troughs across the 24-hour day (Aschoff 1965; Strogatz et al. 1987; Folkard and Barton 1993; Åkerstedt 2007; Scheer et al. 2009). In addition, some major disasters of the past have been associated with night-work-related sleep deprivation and reduced alertness (Mitler et al. 1988).

Only a few studies, however, have looked at sleep and health in shift-workers employed in different shift systems (Czeisler et al. 1982; Orth-Gomer 1983; Barton et al. 1993; van Amelsvoort et al. 2001; Knauth and Hornberger 2003) and one aspect that has been little explored is the accident rate in different shift-work rotations, namely in clockwise and counterclockwise rotations. The aim of the current study was to analyze accident data from male steel workers employed in shift schedules encompassing three different shifts (morning, late, night shifts), rotating in either a clockwise ${ }^{1}$ (e.g., morning to late to night shifts) or counterclockwise $^{2}$ (e.g., night to late to morning shifts) direction. It was hypothesized that the accident rate in the current study would be (i) highest on the night shift, (ii) that it would vary with the length of time on shift and, (iii) that it would be different between the clockwise and counterclockwise rotating shift-workers.

${ }^{1}$ Forward rotating shift system

${ }^{2}$ Backward rotating shift system 


\section{METHODS AND MATERIALS}

Accident data were provided by the Occupational Health Department of ArcelorMittal INDUSTEEL Belgium in Charleroi for the years 2003 to 2010. Due to the global financial crisis starting in 2008, which led to changes in the factory's work patterns and the number of staff on each shift, the data analysis has been restricted to the 5-year period from 2003 through 2007. The accident data for the years 2003 through 2007 were pooled prior to analysis. Typical accidents were stumbling while walking, contusions, bruises, cuts to fingers, or burns, e.g., while handling (often very hot) steel plates. Data were provided with the date and clock time of the accidents and analyzed in hourly bins (e.g., an accident that happened at 14:25 hours was allocated to the "14 hour" bin). To account for the different number of workers on each shift, accident data were analyzed after normalization to a standardized accident count of 100 workers per shift. Data were also analyzed by length of time on shift ( $1^{\text {st }}$ to $8^{\text {th }}$ work hour). Only those accidents for which the direction of the shift schedule (clockwise or counterclockwise) was known have been used for the analysis. Therefore, from a total of $\mathrm{N}=1025$ accidents registered from 2003 through 2007, $578(56 \%)$ accidents that clearly indicated the direction of the shift schedule of the worker involved in the respective accident were analyzed.

\section{Calculation}

Shown in Table 1 are representative examples of a full shift-work cycle for an individual working in a clockwise and counterclockwise rotation, respectively. At this steel factory no other shift systems were employed. The clockwise group at the steel factory worked a faster rotating schedule than the counterclockwise workers. The number of free non-work days within a shift cycle could have been different per worker, and, in addition, the counterclockwise workers had a variable number of free days to choose within a shift-work cycle. The number of free non-work days, however, was the same per year for each worker. The work times for both shift-work rotation groups were 06:00-14:00 h (morning shift), 14:00-22:00 h (late shift), and 22:00-06:00 $\mathrm{h}$ (night shift). At this steel factory the allocation of a worker to either of these two shift patterns was solely dependent on job vacancies offered to a worker applying for a job, and not subject to the workers' choice. Shift-workers have been reported not to switch from one shift rotation to the other. The tasks of the workers in the two shift-work rotations only differed due to their role in 
the steel producing process, and were assumed by the company to be equally labor intensive and stressful.

At the current factory, clockwise workers handled the steel while in its liquid phase (work phase 1 , steel temperatures of $1400-1500^{\circ} \mathrm{C}$ ) and the counterclockwise group processed the steel in its later more solid phase (work phase 2, steel temperature of about $1200{ }^{\circ} \mathrm{C}$ ). Times of rest breaks were not available, however, rest breaks were evenly distributed across each shift, and only depended on the possibilities for rest within a certain work process (e.g., maintenance work, control work or work at the furnace and rolling steel mill). Manual and preparation work was done mainly during the morning shift in both shift rotations. From discussion with the Occupational Health Department we learned that the a priori risk of being involved in an accident at work is not regarded by the Management as dependent upon the direction of shift rotation. In addition, the level of supervision of the workers did not affect the process of reporting an accident, as any accident at any time of day or night in any of the three shifts was first reported to one of three security guards who were located at strategic points in the factory. Each security guard then followed a standardized accident reporting protocol. Data analysis was performed using PASW Statistics 18.0 (IBM, Somers NY, USA) for Macintosh. Parametric and non-parametric statistical analyses were performed as appropriate.

\section{RESULTS}

A total number of 578 accidents for the years 2003 through 2007 were analyzed. There was no age difference ( $\mathrm{p}=0.92$, unpaired Students' $\mathrm{t}$-test) between the workers in the two shift rotations (clockwise: mean 38.1 \pm SD 9.8 years; counterclockwise: mean 38.0 \pm SD 10.1 years). A clear diurnal variation for the accident rates across the 24-hour day was observed in both rotations (Figures $1 \mathrm{~A}$ and $\mathrm{B}$; data are presented as a double-plot for illustrative purposes to better show the 24-hour variation).

The highest accident rate was found in the morning shift (06:00-14:00 h), with a lower rate across the late shift (14:00-22:00 h) and the lowest rate during the night shift (22:00-06:00 h), which was similar in both shift rotations. General linear model analysis showed no interaction between 'shift type' (morning, late, night) and 'length of time on shift' ( $1^{\text {st }}$ to $8^{\text {th }}$ work hour) on the accident rate $(\mathrm{p}=0.116)$. There was no statistically significant difference in the accident rate between the morning, late, and night shifts between the two shift systems (data not shown). 
Within both shift rotations, there was a significant difference in the accident rate between the morning and night shifts (Figure 2), but not between morning and late shifts or between night and late shifts. We correlated the accident rate per hour with the length of time on shift $\left(1^{\text {st }}\right.$ to $8^{\text {th }}$ work hour), to test the hypothesis whether an increased accident rate depended on the length of time a shift-worker had been working. The accident rate did not correlate with the length of time on shift $\left(1^{\text {st }}\right.$ to $8^{\text {th }}$ hour on shift; 2-tailed Pearson correlation), except for the late shift in a counterclockwise rotation $(\mathrm{r}=-0.802, \mathrm{p}=0.017)$, showing a decrease in the accident rate as length of time on shift increased.

\section{DISCUSSION}

The findings of this study to some extent contrast results of previous reports on the accident rate in shift-workers (Mitler et al. 1988; Costa 2003; Folkard et al. 2005). We found that the morning shift rather than the night shift had the highest accident rate in both shift rotations. The a priori risk of being involved in an accident at work was assumed by the company to be similar in both shift rotations. Notably, the 24-hour variation in accident rate was not statistically different between the clockwise and counterclockwise shift schedule in this study. Our findings, therefore, possibly reflect the fact that most of the manual and preparation work was done in the morning shift of both shift rotations. An additional reason for the increased accident rate in the morning shift might be related to the very early shift start at 06:00 h, which means an even earlier time of getting out of bed compounding the problem after a number of free days off. The allocation of work shifts and days off within a shift-work cycle would interfere with entrainment of the circadian clock (Roenneberg et al. 2007; Kantermann et al. 2010) and the sleep/wake pattern in these workers and hence with their adjustability to a certain work shift (Monk et al. 1996; Knauth and Hornberger 2003; Smith et al. 2009; Postnova et al. 2012). This finding may imply that the circadian rhythm in sleepiness and alertness must be assumed to additionally modify accident risk at certain times of the day. Although not statistically different, the accident rate in the morning shift was higher in clockwise compared to counterclockwise workers in the current study. This difference might be partly related to the different allocation of the number of morning shifts and days off within the clockwise and counterclockwise schedule. We can only speculate on this finding as, unfortunately, we have no information about the different shift types and days off within these shift-work cycles. The coincidence of sleep 
deprivation/sleep inertia at the start of the early morning shift with the period of highest physical work for the workers might explain our results.

We were not able to assess the differential effects of the different directions and speeds of the two shift rotations. Rotation and speed could be a confounding factor in the study, which in turn could affect the extent of sleep deprivation of the worker and hence accident rate. To resolve this problem one would need to study two additional rotation groups, namely a fast counterclockwise and a slow clockwise rotation shift, but such shift systems were not employed at this steel factory. However, since there was no statistically significant difference between the accident rate on morning shifts between clockwise and counterclockwise rotation we can assume that any such effect was small in the current study. Future studies of this type, however, in combination with objective physiological measures and, for example, estimates of work monotony (which could affect levels of alertness and performance) are warranted.

In the current study there was a trend of a decreasing accident rate by the number of hours $\left(1^{\text {st }}\right.$ to $\left.8^{\text {th }}\right)$ the counterclockwise workers spent on their late shifts (between 14:00 and 22:00 h). This negative correlation in the accident rate in the counterclockwise late shift over time could be associated with the increased level of alertness and decreased sleepiness reported between 20:00 and 22:00 $\mathrm{h}$ in non-shift-workers, which has been previously described as the "forbidden zone for sleep" (Lavie 1986) or as the "wake maintenance zone" (Strogatz et al. 1987). An effect of the "forbidden sleep zone" on sleep timing in shift-workers has also been previously reported (Folkard and Barton 1993). As sleepiness and alertness were not measured in the current study, we can only speculate on this finding, which suggests that sleepiness and alertness are less affected by the length of time a worker is on shift, but more so by the underlying circadian alerting signal. Therefore, the finding of such positive association with the "forbidden sleep zone" might also indicate that the circadian rhythm in the counterclockwise workers was less phase shifted than in the clockwise workers.

Considering the large number of different shift-work systems employed worldwide, a single solution suitable for all workers will be impossible to establish. Current practices of shiftwork scheduling promote clockwise rotation (Czeisler et al. 1982; Orth-Gomer 1983; Barton et al. 1993; van Amelsvoort et al. 2001; Knauth and Hornberger 2003). This pattern was based inter alia on early studies of time-zone travel showing that westward flights, compared to eastward flights, were accompanied by faster adjustment to a new time zone, due to the fact that 
phase delays of the internal clock are for most people easier to accomplish than phase advances (Knauth and Hornberger 2003; Sack et al. 2007). These considerations may be applicable to some shift-work settings but studies clearly defining the contribution of both the direction and speed of shift rotation to shift-work adjustment are lacking (Costa 2003; Knutsson 2004; Kantermann et al. 2010; Postnova et al. 2012). In real life, for instance, complete adjustment to night work is rare even in permanent night shift-workers (Folkard 2008). Exceptions have been found only in those shift-workers working in unique, adjustment-promoting work environments like oilrigs (Barnes et al. 1998; Gibbs et al. 2002) or workstations in Antarctica (Midwinter and Arendt 1991; Ross et al. 1995). Furthermore, a series of recent shift-work simulation studies has shown that not complete adjustment, but establishment of a compromise phase position, might be more beneficial to facilitate adjustment for those who regularly switch between night and day work (Revell and Eastman 2005; Lee et al. 2006; Smith et al. 2008; Smith and Eastman 2008; Smith et al. 2009). Whether this holds true and is also feasible for rotating shift-workers in real life settings is subject to future studies. Some studies have investigated sleep and health in shiftworkers employed in different rotations arguing in favor of clockwise rotation (Czeisler et al. 1982; Orth-Gomer 1983; Barton et al. 1993; van Amelsvoort et al. 2001; Knauth and Hornberger 2003) but prospective, longitudinal field studies on the differential effects of fast or slow adjustment in clockwise or counterclockwise rotations have not yet been performed.

\section{STRENGTHS AND LIMITATIONS}

The strengths of the current study are the comparison of the accident rate for two different shift-work rotations occurring at the same workplace as well as the precision of the accident data collected with detailed time and date information. The limitations of this study are its retrospective design and the non-availability of supplementary data on work tasks, rest breaks, individual sleep times (especially for the sleep period before the respective shift in which an accident occurred), and sleepiness and alertness levels at work. In addition, we excluded all those accidents that did not clearly indicate the direction of the shift schedule of the worker involved in the respective accident, which has led to a loss of data of $44 \%$. We do not assume that this loss of data affects the accuracy of the remaining data that was used for the analysis negatively. The results of the current study must thus be regarded with caution and be seen as specific for this 
workplace. Follow-up investigations (e.g., using sleep diaries, actimetry, and measurements of the lighting conditions) are needed to investigate these issues further.

\section{CONCLUSION}

Despite its limitations, the results of this study show that (i) it is not always the night shift that shows the highest accident rate, that (ii) the accident rate does not necessarily increase with length of time on shift, and that (iii) the direction of shift rotation might have less impact on accident rate.

\section{ACKNOWLEDGEMENTS}

TK is supported by the DFG (German Research Foundation), TK and DJS are supported by the 6th Framework Project EUCLOCK (018471). Author Contributions: TK analyzed data and wrote manuscript; DH provided data; all authors edited the manuscript. Conflicts of interest: none to declare.

\section{REFERENCES}

Åkerstedt T. 2007. Altered sleep/wake patterns and mental performance. Physiol Behav 90:209-18

Aschoff J. 1965. Circadian rhythms in man. Science 148:1427-32

Barnes RG, Deacon SJ, Forbes MJ, et al. 1998. Adaptation of the 6-sulphatoxymelatonin rhythm in shiftworkers on offshore oil installations during a 2-week 12-h night shift. Neurosci Lett 241:9-12

Barton J, Spelten ER, Smith LR, et al. 1993. A classification of nursing and midwifery shift systems. Internat J Nurs Stud 30:65-80

Costa G. 2003. Factors influencing health of workers and tolerance to shift work. Theor Issues Ergon Sci 4:263-88

Czeisler CA, Moore-Ede MC, and Coleman RH. 1982. Rotating shift work schedules that disrupt sleep are improved by applying circadian principles. Science 217:460-3

Folkard S. 1992. Is there a 'best compromise' shift system? Ergonomics 35:1453-63

Folkard S. 1997. Black times: Temporal determinants of transport safety. Accid Anal Prev 29:417-30

Folkard S. 2008. Do permanent night workers show circadian adjustment? A review based on the endogenous melatonin rhythm. Chronobiol Internat 25:215-24

Folkard S and Barton J. 1993. Does the 'forbidden zone' for sleep onset influence morning shift sleep duration? Ergonomics 36:85-91

Folkard S and Tucker P. 2003. Shift work, safety and productivity. Occup Med (Lond) 53:95-101

Folkard S, Lombardi DA, and Tucker PT. 2005. Shiftwork: Safety, sleepiness and sleep. Indust Health 43:20-3 
Gibbs M, Hampton S, Morgan L, et al. 2002. Adaptation of the circadian rhythm of 6-sulphatoxymelatonin to a shift schedule of seven nights followed by seven days in offshore oil installation workers. Neurosci Lett 325:914

Kantermann T, Juda M, Vetter C, et al. 2010. Shift-work research - where do we stand, where should we go? Sleep and Biological Rhythms 8:95-105

Karlsson BH, Knutsson AK, Lindahl BO, et al. 2003. Metabolic disturbances in male workers with rotating threeshift work. Results of the wolf study. Internat Arch Occup Environ Health 76:424-30

Knauth P and Hornberger S. 2003. Preventive and compensatory measures for shift workers. Occup Med (Lond) 53:109-16

Knutsson A. 2003. Health disorders of shift workers. Occup Med (Lond) 53:103-8

Knutsson A. 2004. Methodological aspects of shift-work research. Chronobiol Internat 21:1037-47

Lavie P. 1986. Ultrashort sleep-waking schedule. Iii. 'gates' and 'forbidden zones' for sleep. Electroencephalogr Clin Neurophysiol 63:414-25

Lee C, Smith MR, and Eastman CI. 2006. A compromise phase position for permanent night shift workers: Circadian phase after two night shifts with scheduled sleep and light/dark exposure. Chronobiol Internat 23:859-75

Midwinter MJ and Arendt J. 1991. Adaptation of the melatonin rhythm in human subjects following night-shift work in Antarctica. Neurosci Lett 122:195-8

Mitler MM, Carskadon MA, Czeisler CA, et al. 1988. Catastrophes, sleep, and public policy: Consensus report. Sleep 11:100-9

Monk TH, Folkard S, and Wedderburn AI. 1996. Maintaining safety and high performance on shiftwork. Appl Ergon 27:17-23

Orth-Gomer K. 1983. Intervention on coronary risk factors by adapting a shift work schedule to biologic rhythmicity. Psychosom Med 45:407-15

Postnova S, Layden A, Robinson PA, et al. 2012. Exploring sleepiness and entrainment on permanent shift schedules in a physiologically based model. J Biol Rhythms 27:91-102

Revell VL and Eastman CI. 2005. How to trick mother nature into letting you fly around or stay up all night. J Biol Rhythms 20:353-65

Roenneberg T, Kuehnle T, Juda M, et al. 2007. Epidemiology of the human circadian clock. Sleep Med Rev 11:42938

Ross JK, Arendt J, Horne J, et al. 1995. Night-shift work in antarctica: Sleep characteristics and bright light treatment. Physiol Behav 57:1169-74

Sack RL, Auckley D, Auger RR, et al. 2007. Circadian rhythm sleep disorders: Part i, basic principles, shift work and jet lag disorders. An American Academy of Sleep Medicine review. Sleep 30:1460-83

Scheer FA, Hilton MF, Mantzoros CS, et al. 2009. Adverse metabolic and cardiovascular consequences of circadian misalignment. Proc Natl Acad Sci USA 106:4453-8 
Smith MR and Eastman CI. 2008. Night shift performance is improved by a compromise circadian phase position: Study 3. Circadian phase after 7 night shifts with an intervening weekend off. Sleep 31:1639-45

Smith MR, Cullnan EE, and Eastman CI. 2008. Shaping the light/dark pattern for circadian adaptation to night shift work. Physiol Behav 95:449-56

Smith MR, Fogg LF, and Eastman CI. 2009. Practical interventions to promote circadian adaptation to permanent night shift work: Study 4. J Biol Rhythms 24:161-72

Strogatz SH, Beersma DG, Enright JT, et al. 1987. The mathematical structure of the human sleep-wake cycle. J Biol Rhythms 2:317-29

van Amelsvoort LG, Schouten EG, Maan AC, et al. 2001. Changes in frequency of premature complexes and heart rate variability related to shift work. Occup Environ Med 58:678-81 
Table 1. Representative examples of two complete shift-work cycles of individuals in fast clockwise and slow counterclockwise rotating schedules.

An individual's fast clockwise shift schedule (example, 28 days)

$\underline{\text { Shift sequence }}$

M - M - L - L - N - N - N - DO - DO

M - M - L - L - L - N - N - DO - DO

M - M - M - L - L - N - N - DO - DO - DO

$\underline{\text { Shift ratio }}$

An individual's slow counterclockwise shift schedule (example, 21 days)

Shift sequence

$\mathrm{N}-\mathrm{N}-\mathrm{N}-\mathrm{N}-\mathrm{N}-\mathrm{N}-\mathrm{DO}$

L - L - L - L - L - L - DO

M - M - M - M - M - M - DO $\underline{\text { Shift ratio }}$

$(\mathrm{M})=$ Morning shift 06:00-14:00 h, (L) = Late shift 14:00-22:00 h, (N) = Night shift 22:0006:00 h, (DO) = day off. Note, the counterclockwise workers had a variable number of free nonwork days to be taken within a shift-work cycle so that each worker had the same number of free non-work days per year. 
Figure 1. Number of accidents (mean \pm SEM) per 100 workers per year for the 5-year period from 2003 through 2007 in (A) fast clockwise and (B) slow counterclockwise rotation across 24 hours. Data are plotted twice (double-plot) to better illustrate the transition between two days; the work times of the morning shift were 06:00-14:00 hours, late shift 14:00-22:00 hours, night shift 22:00-06:00 hours.

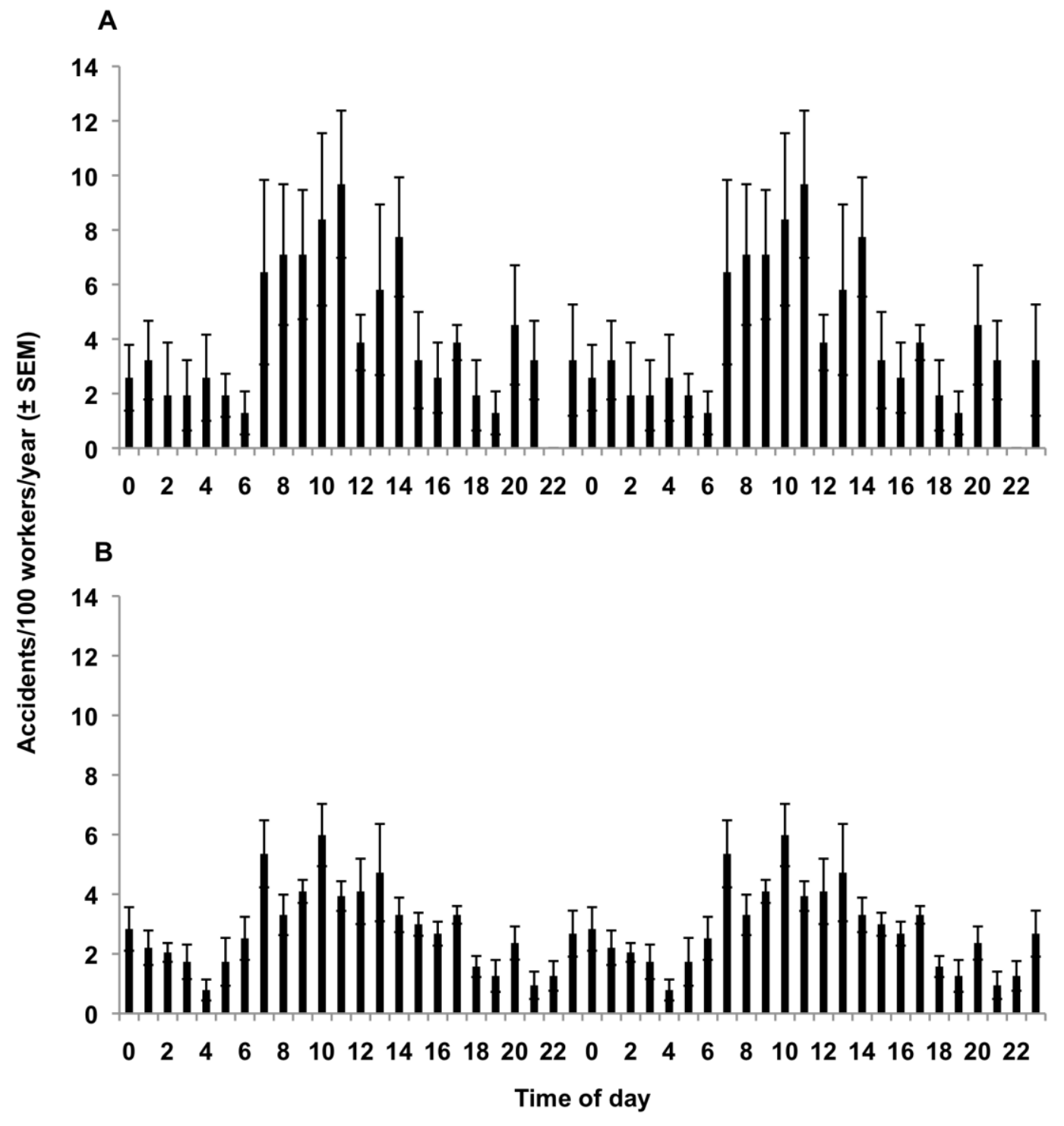


Figure 2. Number of accidents (mean \pm SEM) per 100 workers per year for the 5-year period from 2003 through 2007 in the morning, late and night shift in fast clockwise and slow counterclockwise rotation. In both shift rotations the accident rate was significantly higher in the morning compared to the night shift. $* \mathrm{p}<0.05 ; * * \mathrm{p}<0.01$ compared to corresponding night shift (Dunn's test).

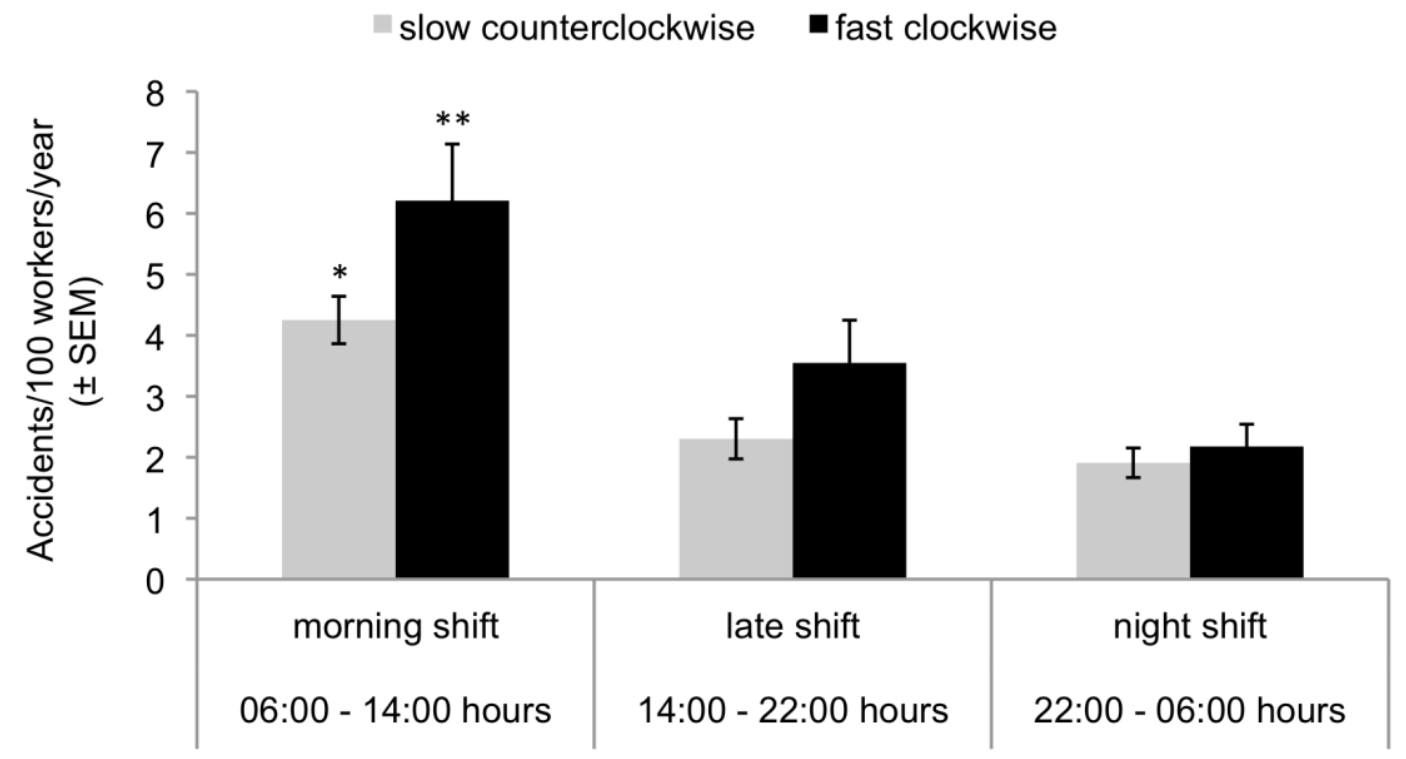

